\title{
Association of neighbourhood food availability with the consumption of processed and ultra-processed food products by children in a city of Brazil: a multilevel analysis
}

\author{
Fernanda Helena Marrocos Leite ${ }^{1, *}$, Elena de Carvalho Cremm, Débora Silva Costa de \\ Abreu ${ }^{1}$, Maria Aparecida de Oliveira ${ }^{1}$, Nadine Budd $^{2}$ and Paula Andrea Martins ${ }^{1}$ \\ 'Department of Human Movement Science, Nutritional Epidemiology Laboratory, Federal University of Sao Paulo, \\ 95 Ana Costa Avenue, Santos, Sao Paulo 11060001 , Brazil: ${ }^{2}$ Centers for Disease Control and Prevention, National \\ Center for Chronic Disease Prevention and Health Promotion, Division of Nutrition, Physical Activity, and Obesity, \\ Atlanta, GA, USA
}

Submitted 18 April 2016: Final revision received 5 November 2016: Accepted 13 December 2016: First published online 18 January 2017

\begin{abstract}
Objective: To investigate the association between neighbourhood food availability and the consumption of ready-to-consume products (RCP), either processed or ultra-processed, and unprocessed/minimally processed foods (UF-MPF) by children.

Design: Cross-sectional. 24h Dietary recalls were collected from children from January 2010 to June 2011. Neighbourhood food availability data were collected from 672 food stores located within $500 \mathrm{~m}$ of participants' homes, using an adapted and validated instrument. Neighbourhood-level socio-economic status (SES) was obtained by calculating the mean years of household head's education level in each census tract covered by $500 \mathrm{~m}$ buffers. Foods that were consumed by children and/or available in the food stores were classified based on their degree of industrial processing. Multilevel random-effect models examined the association between neighbourhood food availability and children's diets.

Setting: Santos, Brazil.

Subjects: Children ( $n$ 513) under 10 years old (292 aged <6 years, 221 aged $\geq 6$ years).

Results: The availability of RCP in food stores was associated with increased RCP consumption $(P<0 \cdot 001)$ and decreased UF-MPF consumption $(P<0 \cdot 001)$. The consumption of UF-MPF was positively associated with neighbourhood-level SES $(P<0 \cdot 01)$, but not with the availability of UF-MPF in the neighbourhood.

Conclusions: Results suggest that food policies and interventions that aim to reduce RCP consumption in Santos and similar settings should focus on reducing the availability in food stores. The results also suggest that interventions should not only increase the availability of UF-MPF in lower-SES neighbourhoods, but should strive to make UF-MPF accessible within these environments.
\end{abstract}

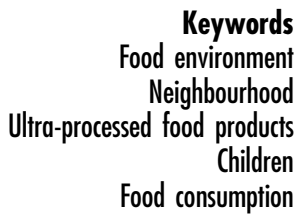

environment

Children

Food consumption
Between 1980 and 2013, worldwide prevalence of overweight and obesity rose by $47.1 \%$ in children $(<18 \text { years })^{(1)}$. In Brazil, data from the 2008-2009 Household Budget Survey reported that one in three children aged 5-9 years was above the weight-for-age recommended by the $\mathrm{WHO}^{(2)}$. Creating initiatives to understand and mitigate obesity has been considered one of the major challenges of the 21st century and childhood obesity prevention has become a global priority ${ }^{(3)}$.

Several studies have demonstrated that both dietary behaviours and the development of obesity and chronic diseases are related to a range of complex social and environmental influences that extend beyond the notion of individual choices ${ }^{(4-11)}$. The food environment can refer to macro- or community-level environments, such as the type, density, location and proximity to food outlets (e.g. food stores and restaurants) as well as other sources of food (e.g. home, schools, worksites), and micro- or consumer-level environments, which include in-store availability of healthy and unhealthy options, price, quality and promotions ${ }^{(12)}$. Food behaviours can also be mediated by psychosocial, demographic and perceived environment variables ${ }^{(12,13)}$. Thus, socioecological and systems-oriented frameworks have been increasingly used 
to explore the interactions between individual and food environment variables and to identify promising intervention strategies ${ }^{(14-16)}$.

In the case of Brazil and some high-income countries, community food environments commonly frequented by children and their caregivers, such as supermarkets, restaurants, schools, or recreation and sports settings, are replete with highly processed energy-dense and nutrient-poor food items that oppose recommendations presented by nutritional guidelines ${ }^{(4,17-19)}$. A study that evaluated the surrounding areas of three public schools in a Brazilian urban area found a high concentration of ultra-processed food products (UPP) in the food stores that were located closer to these institutions, demonstrating that children experienced greater exposure to UPP before and after school ${ }^{(20)}$.

UPP dominate the food supplies of higher-income countries and UPP consumption is expanding rapidly in developing countries ${ }^{(21,22)}$. National food expenditure surveys conducted in the UK and Canada showed that 63.4 and $61.7 \%$ of dietary energy, respectively, came from readyto-consume products (RCP) ${ }^{(23,24)}$. In Brazil, a developing country, the contribution of RCP to dietary energy has also risen steadily, from 20.3 to $32.1 \%$ in households located in metropolitan areas in the last three decades ${ }^{(25)}$.

Processed and ultra-processed food products are problematic not only because they are high in energy, fat, sugar and sodium, but also because they are designed to be palatable, convenient and inexpensive to encourage purchase and subsequent overconsumption ${ }^{(26,27)}$. Several studies have demonstrated positive associations between the consumption of UPP and weight gain and chronic diseases in a range of age groups ${ }^{(28-31)}$. Another harmful effect especially for children is the displacement of the consumption of unprocessed/minimally processed foods (UF-MPF) and meals by these products and snacks, leading to a shift away from traditional dietary patterns and foodways based on meals prepared and shared with family and others ${ }^{(21,32)}$.

In high-income countries, both the existence of different types of food store and the higher availability of unhealthy foods close to children's homes and schools are associated with poor eating habits and obesity ${ }^{(33-37)}$. In Brazil, less is known about the association between the food environment, including availability of RCP, and the food consumption of children. Therefore, the present study investigated the associations between the neighbourhood availability of RCP and UF-MPF in food stores and the consumption of these food items by children residing in the city of Santos. The main hypothesis tested was whether higher availability of RCP and UF-MPF in food stores would result in significantly greater consumption of these items by children living within $500 \mathrm{~m}$ from respective food stores. The secondary research question sought to determine if higher availability of RCP was associated with a decreased consumption of UF-MPF. To our knowledge, no prior study has examined associations between the availability of RCP and children's consumption of these foods in Brazil.

\section{Methods}

\section{Study design and setting}

The Nutritional Environment Assessment in the City of Santos, Brazil (AMBNUT) was a cross-sectional study conducted from January 2010 to June 2011 to evaluate environmental influences on dietary intake and nutritional status of children under 10 years old and their mothers. The city of Santos has a total area of $280.7 \mathrm{~km}^{2}$, with 419400 inhabitants concentrated in $39.4 \mathrm{~km}^{2}$ of urban area and a poverty incidence of $4.54 \%{ }^{(38)}$. It is located near the metropolitan region of Sao Paulo, the largest Brazilian city, and it has the biggest seaport in Latin America. The study was approved by the Ethics and Research Committee of the Federal University of Sao Paulo (protocol number CEP 0275/09 and 0276/09).

\section{Sampling}

The AMBNUT research team collected data on 539 children under 10 years of age. Food consumption data were incomplete for eleven children and fifteen children were exclusively breast-fed. Therefore, twenty-six children were dropped from the study, leaving a final sample of 513 children ( 292 aged $<6$ years, 221 aged $\geq 6$ years). This total exceeds the number obtained in the sample size calculation determined a priori ( $n$ 206) for a different study hypothesis that was part of the AMBNUT research, regarding prevalence of nutrient inadequacy in the target population (children under 10 years), estimated at $44 \%^{(39,40)}$, with a margin of error of $5 \%$, a confidence interval of $95 \%$ and a subject loss of $10 \%$.

Households were recruited by stratified random sampling of thirty-five census tracts (out of 564 census tracts) designed to be proportional to the administrative areas of the urban territory (10\% downtown, $20 \%$ northwest and $60 \%$ seafront). After the selection of census tracts, sectors were enrolled for the identification of eligible households. Children were eligible for the study if they: (i) were under 10 years old; (ii) were a resident of the household; and (iii) did not have any medical conditions that would affect food intake and nutritional status. According to the sampling design initially planned, twenty eligible households were to be randomly chosen from each census tract. However, since the inclusion and exclusion criteria greatly limited this number, all children identified in a given tract, and whose mothers agreed to participate in the study, were assessed from January 2010 to June 2011, until twenty interviews were obtained. Three attempts were made at every household to conduct an interview. If there was more than one eligible child in the household, a simple random selection was performed to determine which child would be included. After the 
identification of eligible households, mothers and their children were asked to participate in the study, and interviews were conducted after signing the consent form. The response rate was $70 \cdot 3 \%$ when considering the interviews done at the eligible households and an average of sixteen mother-child interviews were conducted per census tract. The loss rate was similarly distributed throughout Santos city and did not cause an impact on the present study's results.

The environment sample consisted of all food stores located in $97 \%$ of the urban area of the city of Santos ( $n$ 672), except those only open during the night. The recruitment of food stores occurred simultaneously to the recruitment of households from January 2010 to June 2011 by different pairs of trained data collectors. Food stores were defined as establishments where people buy food and prepare or consume it elsewhere, such as grocery stores or supermarkets, convenience stores, farmers' markets, produce markets, bakeries, butcheries, candy stores and street food stands ${ }^{(13)}$. The establishments were assessed only after authorization by the respective storeowners, and their recruitment involved explanation of the purpose of the study and distribution of recruitment materials explaining frequently asked questions and answers. A total of twenty-one storeowners (3.1\%) refused to participate in the study. All places opened to the public where people were able to sit and eat, such as sit-down and fast-food restaurants, were excluded from the sample.

\section{Data collection}

\section{Individual-level measures}

The questionnaire used for the present study has been described previously elsewhere ${ }^{(11)}$ and was used to collect information on household demographic and socioeconomic factors, children's height/weight and food intake via $24 \mathrm{~h}$ recalls. Interviews typically lasted $100 \mathrm{~min}$ and were conducted by trained data collectors.

The $24 \mathrm{~h}$ recall (via caregiver proxy) was administered twice and spaced 15 to $90 \mathrm{~d}$ apart, in order to account for within-person variation ${ }^{(41)}$. The method used to account for this variation was described previously by Slater et $a l .{ }^{(42)}$. Other methodological procedures applied in order to reduce the variation given by the measurement error of the instrument utilized were: (i) three pairs of data collectors were selected and trained on the correct use of the instrument, and at least one member of the pair was a dietitian; (ii) an adapted version of the multiple-pass method was used in data collection ${ }^{(43,44)}$; and (iii) standard utensils, a photograph album containing pictures of commonly consumed foods and drinks ${ }^{(45)}$, and food models were used to help respondents with portion size estimates. For children who were enrolled in either public or private schools and whose caregiver reported the consumption of meals/foods offered by these institutions, menus and recipes were obtained via email and/or telephone calls. To standardize the portion sizes of consumed foods, two references were used: (i) the handbook of recipes and home measures for nutritional surveys calculation, $2002^{(46)}$; and (ii) the table for the evaluation of food intake in household measures, 5th edition, $2004^{(47)}$.

The degree of industrial processing of the foods consumed by the study sample was assessed using the food classification system proposed by Monteiro et $a l .{ }^{(48)}$ and incorporated in the new dietary guidelines for the Brazilian population ${ }^{(49)}$. The 'NOVA Classification System'(50) classifies foods into three groups based on the nature, extent and purpose of food processing: Group 1 comprising unprocessed foods and minimally processed foods (UF-MPF); Group 2 comprising processed culinary ingredients to be combined with foods to make meals and dishes (PCI); and Group 3 comprising ready-to-consume products (RCP), which can be either processed or ultra-processed.

In the current study, all foods that were recorded in the two $24 \mathrm{~h}$ recalls were classified according to the above criteria (Table 1) and the total amount (grams) consumed from each of the groups was calculated. All foods used in culinary preparations were recorded to obtain the amount of each ingredient (grams) and the proportions of UF-MPF, PCI and RCP were calculated.

Table 1 Food and beverage classification based on the degree of industrial processing. Santos, Brazil, 2010

\begin{tabular}{|c|c|}
\hline Food group & Example \\
\hline $\begin{array}{l}\text { Group 1: Unprocessed or minimally processed } \\
\text { foods (UF-MPF) }\end{array}$ & $\begin{array}{l}\text { Fresh, chilled, frozen, vacuum-packed fruits, vegetables, fungi, tubers and roots; dried } \\
\text { fruits and } 100 \% \text { unsweetened fruit juices; grains (cereals) in general; fresh, frozen and } \\
\text { dried beans and other pulses; unsalted nuts and seeds; fresh dried, chilled, frozen } \\
\text { meats, poultry and fish; fresh and pasteurized milk, fermented milk such as plain } \\
\text { yoghurt; eggs; teas, coffee, herb infusions }\end{array}$ \\
\hline Group 2: Processed culinary ingredients (PCI) & $\begin{array}{l}\text { Vegetable oils, butter, milk, cream, lard and margarine; sugar, sweeteners in general; salt; } \\
\text { starches, flours, and 'raw' pastas and noodles (made from flour and water) }\end{array}$ \\
\hline Group 3: Ready-to-consume products (RCP) & $\begin{array}{l}\text { Processed food products: vegetables or legumes preserved in brine, fruits in syrup, fish } \\
\text { preserved in oil, salted or smoked fish or meat, and cheeses with added salt } \\
\text { Ultra-processed food products: biscuits (cookies), cakes and pastries, breads; chocolates, } \\
\text { confectionery (candies), cereal bars, breakfast cereal with added sugar; chips, crisps; } \\
\text { sauces; savoury and sweet snack products; ready-to-eat pasta/pizza and meat, poultry } \\
\text { and fish dishes; processed meat, including chicken nuggets, hot dogs, sausages, } \\
\text { burgers, fish sticks; sugared fruit and milk drinks and sugared and 'no-cal' soft drinks; } \\
\text { powdered juice, infant formula, follow-on milk, baby foods }\end{array}$ \\
\hline
\end{tabular}




\section{Neighbourbood-level measures}

An adapted and validated instrument based on the Nutritional Environment Measurement Survey instrument for stores (NEMS-S) was used by trained data collectors to evaluate the food environment ${ }^{(13)}$. This instrument captures information on food availability, quality and price of food purchases in the context of Brazil, a developing country ${ }^{(51)}$.

Food store assessments included 5 min interviews with managers to collect information about their store's functioning and the main products sold, and a record of the availability of the thirty-three food groups listed in the instrument, determined by observing the food items on the shelves. Availability was recorded in a checkbox corresponding to each food item.

The establishments were classified into ten different categories, according to the purpose of their retail: (i) butcher/poultry shop/fishery; (ii) fresh pasta store; (iii) small full-service store/delicatessen; (iv) bakery; (v) street food stand; (vi) grocery store or supermarket; (vii) convenience store; (viii) produce store; (ix) farmer's market/fresh food stall; and (x) candy store. In the current study, the term 'grocery stores' was used when referring to 'mercados', which are very similar to supermarkets, but smaller (small/medium size). These types of establishment are more common in Brazil than large supermarkets and hypermarkets ${ }^{(52,53)}$.

The availability of foods by degree of industrial processing in food stores was evaluated by using the same classification described in Table 1 . Food stores were further categorized as Higher \% RCP (percentage of RCP higher than percentage of UF-MPF and PCI) or Higher \% UF-MPF (percentage of UF-MPF and PCI higher than percentage of RCP). For this classification we grouped PCI with UF-MPF, since only one type of establishment offered PCI in a higher amount than the other groups. This decision was also based on the new dietary guidelines for the Brazilian population which consider that, when combined with natural or minimally processed foods and used in small amounts, PCI enable the creation of varied and nutritious prepared dishes and meals ${ }^{(49)}$.

\section{Spatial data}

Geographic coordinates (latitude and longitude) of all the households and food stores were collected using a portable GPS (Global Positioning System; Garmin model eTrex), positioned at a distance of $1 \mathrm{~m}$ from the main entrance of each store, and entered into a Geographic Information System (GIS).

The environment variables used in the study were calculated from the GIS by using the overlay procedure. A layer of buffers with a radius of $500 \mathrm{~m}$, which were calculated from each census tract centroid, was created. After the superposition of this layer with another layer containing store-level data, the average values of the measurements that evaluated the availability of foods were calculated to each buffer, providing the information of every census tract neighbourhood. The decision of delineating the neighbourhood as the area within a $500 \mathrm{~m}$ radius buffer was made based on previous studies that have evaluated parents' perception of a safe walking distance for children ${ }^{(54)}$; and the associations between the food environment and children's food consumption ${ }^{(33,55)}$. The spatial analyses were performed in both TerraView (version 3.3.1; INPE) and ArcMap (version 9.3.1; ESRI) programs.

\section{Covariates}

Individual-level variables such as gender, age and socioeconomic status (SES; mean years of mother's education level), and neighbourhood-level SES, were used as potential covariates in the present study. Neighbourhoodlevel SES was obtained from the mean years of household head's education level in all census tracts that fell within a $500 \mathrm{~m}$ radius buffer zone from the sampled census tract centroid by using GIS. The selection of the covariates was based on both the association of SES (e.g. education) with consumption of highly processed foods ${ }^{(56-58)}$ and their inclusion in other research that evaluated the food environment and youth ${ }^{(59-62)}$.

\section{Data analyses}

Descriptive analyses were used to describe both individual and neighbourhood characteristics of the study sample. Multilevel random-effect models were carried out to evaluate the relationship between the availability of RCP in food stores surrounding households and the likelihood of children increasing RCP consumption and decreasing UF-MPF consumption.

Initially, descriptive and univariate analyses were performed in order to investigate the distribution of the outcome and both food environment variables and covariates. The outcome variables used in the models were proportion (\%) of RCP consumption and proportion (\%) of UF-MPF consumption. Food availability was evaluated using six different variables: proportion of food stores classified as Higher \% RCP and proportion of food stores classified as Higher \% UF-MPF; average number ( $n$ ) of items classified as RCP and UF-MPF in the food stores (in the buffers); and percentage (\%) of items classified as RCP and UF-MPF in the food stores (in the buffers). Then, the modelling procedure was carried out through a series of stages. A null model was first used to determine the intra-class correlation coefficient, which provides an estimation of the proportion of variation in the study outcomes due to differences between buffers. Second, bivariate models between the outcomes and each covariate were examined. Finally, the multivariate model-building process began with the introduction of the covariates and the environment variables. Three different multivariate models for each outcome variable were tested by using the main environment variables identified in 
the bivariate models. A likelihood ratio test comparing the deviances of the models and a significance level of $P \leq 0.05$ were used. All analyses were performed using the statistical software package SPSS version 16.0 and MIWin 2.22 (Centre for Multilevel Modelling, University of Bristol, UK).

\section{Results}

\section{Description of the study sample}

Individual and neighbourhood-level characteristics of the study sample are presented in Table 2. Most of the

Table 2 Individual- and neighbourhood-level characteristics of urban children in Santos, Brazil, 2010 ( $n$ 513)

\begin{tabular}{|c|c|c|c|}
\hline Variable & & $n$ & $\%$ \\
\hline \multicolumn{4}{|l|}{ Gender } \\
\hline Male & & 272 & 53.0 \\
\hline Female & & 241 & $47 \cdot 0$ \\
\hline \multicolumn{4}{|l|}{ Age (years) } \\
\hline$<6$ & & 292 & $56 \cdot 9$ \\
\hline$\geq 6$ & & 221 & $43 \cdot 1$ \\
\hline \multicolumn{4}{|l|}{ Nutritional status* } \\
\hline Normal weight $(\mathrm{BMIZ}<1)$ & & 319 & $62 \cdot 7$ \\
\hline Overweight or obese (BMIZ $\geq 1)$ & & 190 & $37 \cdot 3$ \\
\hline \multicolumn{4}{|l|}{ Individual-level SES } \\
\hline \multicolumn{4}{|l|}{ Mother's education level } \\
\hline Primary education or less & & 89 & $17 \cdot 3$ \\
\hline \multirow[t]{2}{*}{ More than primary education } & & 424 & $82 \cdot 7$ \\
\hline & Mean & SD & Median \\
\hline \multicolumn{4}{|l|}{ Neighbourhood-level SES } \\
\hline $\begin{array}{l}\text { Household head's education level - CT } \\
\text { (years) }\end{array}$ & $8 \cdot 8$ & $2 \cdot 1$ & $9 \cdot 0$ \\
\hline \multicolumn{4}{|l|}{ Proportion of consumption (\%) } \\
\hline RCP & 36.95 & $20 \cdot 62$ & $35 \cdot 86$ \\
\hline $\mathrm{PCl}$ & 11.52 & 7.52 & $10 \cdot 24$ \\
\hline UF-MPF & 51.53 & $20 \cdot 47$ & 52.04 \\
\hline
\end{tabular}

BMIZ, BMI-for-age $Z$-score; SES, socio-economic status; CT, census tract; $\mathrm{RCP}$, ready-to-consume products; $\mathrm{PCl}$, processed culinary ingredients: UF-MPF, unprocessed/minimally processed foods.

${ }^{*} n 509$ (four missing-values). participants were $<6$ years of age, male and normal weight, although a high percentage of excess weight (BMI-for-age $Z$-score $>1$ ) was observed (37-3\%). The average proportion of UF-MPF and PCI consumed was higher than the proportion of RCP, although a relevant contribution of RCP to children's consumption was observed. Most mothers had studied beyond primary school (82.7\%) and the average length of education for all census tracts in the city was 8.8 years.

Food store categories and classifications are described in Table 3. Farmers' markets/fresh food stalls, bakeries and grocery stores/supermarkets were the most common types of food store available in Santos. Only produce stores, farmers' markets/fresh food stalls and butchers/poultry shops/fisheries had higher UF-MPF availability compared with the other food sources (Fig. 1); therefore, $60 \cdot 6 \%$ of food sources were classified as Higher \% RCP. The food stores that had the highest proportion of RCP were bakeries, grocery stores/supermarkets, candy stores, convenience stores and street food stands (Table 3).

\section{Associations between the food environment and children's food consumption}

Results of multilevel regression models, which tested associations between food environment variables and outcomes (consumption of RCP and UF-MPF), are presented in Tables 4 and 5 . Higher consumption of RCP was positively associated with the proportion of food stores classified as Higher \% RCP in the buffer (model 4), and both the number (model 5) and proportion (model 6) of items classified as RCP within the food stores. The intraclass correlation coefficient values of the models ranged between 0.01 and 0.02 , indicating that only a small part of the variability in the data can be explained by the grouping analysis; in this case, the census tracts (Table 4).

No association was found between the availability of UF-MPF in food stores and the proportion of consumption

Table 3 Food store categories and classification based on the degree of industrial processing of foods available ( $n$ 672). Santos, Brazil, 2010

\begin{tabular}{|c|c|c|c|c|c|c|c|c|c|c|c|c|}
\hline \multirow[b]{3}{*}{ Food store category } & & & \multicolumn{4}{|c|}{ Classification } & \multicolumn{6}{|c|}{ Food items } \\
\hline & \multicolumn{2}{|c|}{$\begin{array}{l}\text { Total } \\
(n 672)\end{array}$} & \multicolumn{2}{|c|}{$\begin{array}{l}\text { Higher \% RCP } \\
\text { (n 407) }\end{array}$} & \multicolumn{2}{|c|}{$\begin{array}{l}\text { Higher \% UF-MPF } \\
\text { ( }(\text { 265) }\end{array}$} & \multicolumn{2}{|c|}{$\mathrm{RCP}$} & \multicolumn{2}{|c|}{ UF-MPF } & \multicolumn{2}{|c|}{$\mathrm{PCl}$} \\
\hline & $n$ & $\%$ & $n$ & $\%$ & $n$ & $\%$ & Mean & $\%$ & Mean & $\%$ & Mean & $\%$ \\
\hline Butcher/poultry shop/fishery & 72 & $10 \cdot 7$ & 22 & $30 \cdot 6$ & 50 & 69.4 & 4.9 & 38.8 & 3.5 & 51.5 & $1 \cdot 3$ & 9.7 \\
\hline Fresh pasta store & 10 & 1.5 & 9 & $90 \cdot 0$ & 1 & $10 \cdot 0$ & 7.9 & 68.9 & $2 \cdot 0$ & $14 \cdot 2$ & 1.6 & $16 \cdot 9$ \\
\hline Small full-service store/delicatessen & 62 & 9.2 & 47 & $75 \cdot 8$ & 15 & $24 \cdot 2$ & 9.2 & $58 \cdot 1$ & 4.5 & $29 \cdot 1$ & $2 \cdot 0$ & $12 \cdot 8$ \\
\hline Bakery & 118 & $17 \cdot 6$ & 118 & $100 \cdot 0$ & 0 & 0.0 & $17 \cdot 6$ & $67 \cdot 3$ & $6 \cdot 1$ & 22.5 & $2 \cdot 7$ & $10 \cdot 2$ \\
\hline Street food stand & 5 & 0.7 & 5 & $100 \cdot 0$ & 0 & 0.0 & $2 \cdot 3$ & $100 \cdot 0$ & 0.0 & 0.0 & 0.0 & 0.0 \\
\hline Grocery store/supermarket & 109 & $16 \cdot 2$ & 102 & 93.6 & 7 & 6.4 & $16 \cdot 8$ & $56 \cdot 8$ & $9 \cdot 8$ & $32 \cdot 8$ & 2.9 & $10 \cdot 4$ \\
\hline Convenience store & 33 & 4.9 & 33 & $100 \cdot 0$ & 0 & 0.0 & $9 \cdot 8$ & 88.0 & 1.4 & 10.5 & 0.2 & 1.5 \\
\hline Produce store & 9 & 1.3 & 1 & 11.1 & 8 & 88.9 & 4.6 & $29 \cdot 3$ & $5 \cdot 8$ & $61 \cdot 1$ & 1.6 & $9 \cdot 6$ \\
\hline Farmers' market/fresh food stall & 190 & $28 \cdot 3$ & 6 & $3 \cdot 2$ & 184 & 96.8 & 0.4 & $6 \cdot 3$ & 1.8 & $91 \cdot 1$ & 0.2 & $2 \cdot 6$ \\
\hline Candy store & 64 & 9.5 & 64 & $100 \cdot 0$ & 0 & 0.0 & 6.4 & 83.6 & 1.3 & 14.0 & 0.4 & $2 \cdot 4$ \\
\hline
\end{tabular}

$\mathrm{RCP}$, ready-to-consume products; UF-MPF, unprocessed/minimally processed foods; PCI, processed culinary ingredients. 


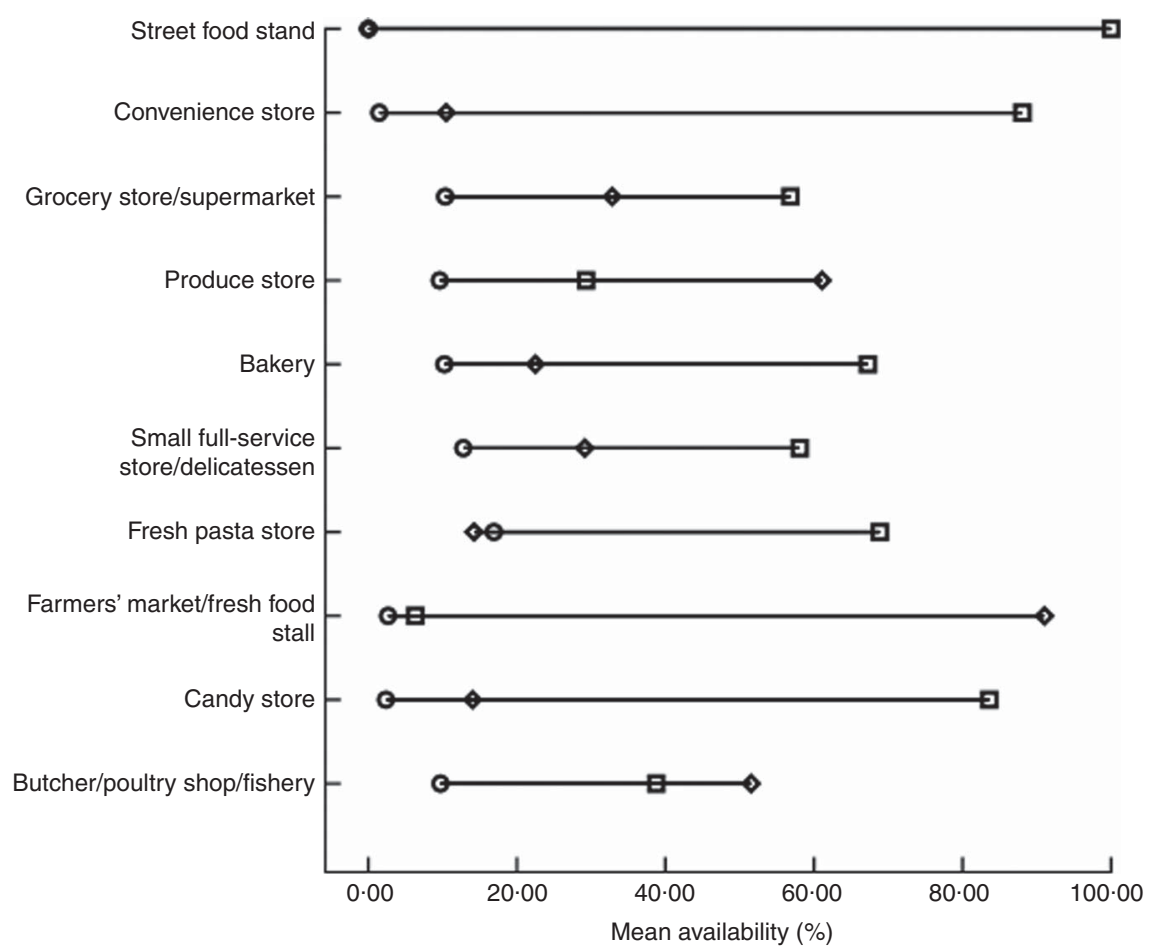

Fig. 1 Availability of foods with different degrees of industrial processing ( $\diamond$, unprocessed/minimally processed foods; O, processed culinary ingredients; $\square$, ready-to-consume products) according to category of food store. Santos, Brazil, 2010.

Table 4 Associations between neighbourhood environment measures and children's consumption of ready-to-consume products using multilevel linear regression models ( $n$ 513). Santos, Brazil, 2010

\begin{tabular}{|c|c|c|c|c|c|c|c|c|c|c|c|c|}
\hline & \multicolumn{2}{|c|}{ Model 1} & \multicolumn{2}{|c|}{ Model 2} & \multicolumn{2}{|c|}{ Model 3} & \multicolumn{2}{|c|}{ Model 4} & \multicolumn{2}{|c|}{ Model 5} & \multicolumn{2}{|c|}{ Model 6} \\
\hline & $\beta$ & SE & $\beta$ & SE & $\beta$ & SE & $\beta$ & SE & $\beta$ & $\mathrm{SE}$ & $\beta$ & SE \\
\hline \multicolumn{13}{|l|}{ Fixed effect } \\
\hline \multicolumn{13}{|l|}{ Individual level } \\
\hline Age (months) & & & $0.13^{* \star *}$ & 0.02 & $0.13^{* \star *}$ & 0.02 & $0.13^{* * \star}$ & 0.02 & $0 \cdot 13^{\star \star \star}$ & 0.02 & $0.13^{* * *}$ & 0.02 \\
\hline Gender (ref.: male) & & & $-1 \cdot 16$ & 1.79 & $-1 \cdot 14$ & 1.79 & -1.08 & 1.79 & -1.04 & 1.78 & -1.04 & 1.78 \\
\hline $\begin{array}{l}\text { Mother's education level } \\
\text { (ref.: more than primary } \\
\text { education) }\end{array}$ & & & $-2 \cdot 30$ & $2 \cdot 34$ & $-2 \cdot 51$ & $2 \cdot 41$ & $-2 \cdot 67$ & 2.40 & $-2 \cdot 83$ & 2.40 & $-2 \cdot 83$ & $2 \cdot 40$ \\
\hline \multicolumn{13}{|l|}{ Neighbourhood level } \\
\hline $\begin{array}{l}\text { Household head's education } \\
\text { level - CT (years) }\end{array}$ & & & & & $-0 \cdot 18$ & 0.47 & -0.40 & 0.47 & -0.53 & 0.47 & -0.53 & 0.47 \\
\hline $\begin{array}{l}\text { Proportion of Higher \% RCP } \\
\text { food stores }(\%)\end{array}$ & & & & & & & $0.09^{*}$ & 0.04 & & & & \\
\hline $\begin{array}{l}\text { Average number of RCP in } \\
\text { the food stores }\end{array}$ & & & & & & & & & $0 \cdot 77^{\star *}$ & 0.28 & & \\
\hline $\begin{array}{l}\text { Proportion of RCP in the } \\
\text { food stores }(\%)\end{array}$ & & & & & & & & & & & $0.14^{\star *}$ & 0.06 \\
\hline \multicolumn{13}{|l|}{ Random effect } \\
\hline$\delta u_{0}$ & 13.87 & $20 \cdot 25$ & $15 \cdot 28$ & 19.55 & $16 \cdot 43$ & $19 \cdot 81$ & $9 \cdot 60$ & $18 \cdot 07$ & 5.07 & $16 \cdot 81$ & 9.41 & 18.04 \\
\hline$\delta e$ & $436 \cdot 20$ & $32 \cdot 78$ & 408.90 & 30.93 & 407.73 & 30.96 & $410 \cdot 66$ & 30.51 & $412 \cdot 88$ & 30.18 & 410.92 & 30.51 \\
\hline Intercept & 36.03 & 0.96 & 37.02 & 1.32 & 37.07 & 1.32 & 36.98 & 1.31 & $36 \cdot 94$ & 1.30 & 37.02 & $1 \cdot 31$ \\
\hline ICC & \multicolumn{2}{|c|}{0.030} & \multicolumn{2}{|c|}{0.036} & \multicolumn{2}{|c|}{0.038} & \multicolumn{2}{|c|}{$\begin{array}{c}30.90 \\
0.023\end{array}$} & \multicolumn{2}{|c|}{0.012} & \multicolumn{2}{|c|}{0.022} \\
\hline Deviance & \multicolumn{2}{|c|}{4723.56} & \multicolumn{2}{|c|}{4692.07} & \multicolumn{2}{|c|}{4691.93} & \multicolumn{2}{|c|}{4687.63} & \multicolumn{2}{|c|}{4684.96} & \multicolumn{2}{|c|}{$4687 \cdot 74$} \\
\hline
\end{tabular}

Ref., reference category; CT, census tract; RCP, ready-to-consume products; ICC, intra-class correlation coefficient.

Model 1, null; model 2, individual-level variables (age, gender and mother's education level); model 3, socio-economic status at the neighbourhood level (mean years of household head's education level - all CT); model 4, first food environment variable (proportion of Higher \% RCP food stores); model 5, second food environment variable (average number of items classified as RCP in the food stores); model 6, third food environment variable (proportion of items classified as $\mathrm{RCP}$ in the food stores).

${ }^{\star} P<0.05,{ }^{* *} P<0.01,{ }^{* *} P<0.001$.

of these foods by the children, after adjustment for individual variables (data not shown). However, a $10 \%$ increase in the proportion of food stores classified as
Higher \% RCP in the neighbourhood (model 4), a 10-unit increase in the average number of items classified as RCP available in the food stores (model 5) and a $10 \%$ increase 
Table 5 Associations between neighbourhood environment measures and children's consumption of unprocessed/minimally processed foods using multilevel linear regression models ( $n$ 513). Santos, Brazil, 2010

\begin{tabular}{|c|c|c|c|c|c|c|c|c|c|c|c|c|}
\hline & \multicolumn{2}{|c|}{ Model 1} & \multicolumn{2}{|c|}{ Model 2} & \multicolumn{2}{|c|}{ Model 3} & \multicolumn{2}{|c|}{ Model 4} & \multicolumn{2}{|c|}{ Model 5} & \multicolumn{2}{|c|}{ Model 6} \\
\hline & $\beta$ & SE & $\beta$ & SE & $\beta$ & SE & $\beta$ & SE & $\beta$ & SE & $\beta$ & SE \\
\hline \multicolumn{13}{|l|}{ Fixed effect } \\
\hline \multicolumn{13}{|l|}{ Individual level } \\
\hline Age (months) & & & $-0.18^{\star \star \star}$ & 0.02 & $-0.19^{\star \star \star}$ & 0.02 & $-0.19^{\star \star *}$ & 0.02 & $-0.19^{\star \star \star}$ & 0.02 & $-0.19^{\star \star \star}$ & 0.02 \\
\hline Gender (ref.: male) & & & $2 \cdot 10$ & 1.78 & 1.97 & 1.77 & 1.90 & $1 \cdot 76$ & 1.85 & 1.76 & 1.91 & 1.76 \\
\hline $\begin{array}{l}\text { Mother's education level } \\
\text { (ref.: more than primary } \\
\text { education) }\end{array}$ & & & -0.43 & $2 \cdot 32$ & 0.64 & $2 \cdot 38$ & $0 \cdot 76$ & $2 \cdot 37$ & 0.89 & $2 \cdot 37$ & $0 \cdot 88$ & $2 \cdot 37$ \\
\hline \multicolumn{13}{|l|}{ Neighbourhood level } \\
\hline $\begin{array}{l}\text { Household head's education } \\
\text { level - CT (years) }\end{array}$ & & & & & $0.88^{\star}$ & 0.46 & $1 \cdot 13^{\star *}$ & 0.46 & $1 \cdot 27^{\star \star}$ & 0.46 & $0.97^{\star \star}$ & 0.44 \\
\hline $\begin{array}{l}\text { Proportion of Higher \% RCP } \\
\text { food stores (\%) }\end{array}$ & & & & & & & $-0 \cdot 11^{\star \star}$ & 0.04 & & & & \\
\hline $\begin{array}{l}\text { Average number of RCP in } \\
\text { the food stores }\end{array}$ & & & & & & & & & $-0.84^{\star \star \star}$ & $0 \cdot 27$ & & \\
\hline $\begin{array}{l}\text { Proportion of RCP in the } \\
\text { food stores (\%) }\end{array}$ & & & & & & & & & & & $-0.17^{\star \star}$ & 0.06 \\
\hline \multicolumn{13}{|l|}{ Random effect } \\
\hline$\delta u_{0}$ & 7.36 & $19 \cdot 39$ & $12 \cdot 16$ & $18 \cdot 67$ & 14.46 & $19 \cdot 00$ & $5 \cdot 23$ & $16 \cdot 51$ & 0.384 & $15 \cdot 00$ & $3 \cdot 37$ & $15 \cdot 95$ \\
\hline$\delta e$ & 464.03 & $34 \cdot 10$ & $404 \cdot 12$ & $30 \cdot 30$ & 399.12 & $30 \cdot 16$ & 403.40 & 29.52 & $405 \cdot 81$ & $29 \cdot 11$ & 404.43 & $29 \cdot 38$ \\
\hline Intercept & $52 \cdot 89$ & 0.96 & 51.94 & 1.30 & 51.75 & 1.30 & 51.84 & 1.28 & 51.87 & 1.27 & 51.82 & 1.28 \\
\hline ICC & \multirow{2}{*}{\multicolumn{2}{|c|}{$\begin{array}{c}0.015 \\
4748.43\end{array}$}} & \multirow{2}{*}{\multicolumn{2}{|c|}{$\begin{array}{c}0.029 \\
4682 \cdot 40\end{array}$}} & \multirow{2}{*}{\multicolumn{2}{|c|}{$\begin{array}{c}0.034 \\
4678.74\end{array}$}} & \multirow{2}{*}{\multicolumn{2}{|c|}{$\begin{array}{c}0.012 \\
4673.04\end{array}$}} & \multirow{2}{*}{\multicolumn{2}{|c|}{$\begin{array}{c}0.001 \\
4670 \cdot 00\end{array}$}} & \multirow{2}{*}{\multicolumn{2}{|c|}{$\begin{array}{c}0.008 \\
4672 \cdot 04\end{array}$}} \\
\hline Deviance & & & & & & & & & & & & \\
\hline
\end{tabular}

Ref., reference category; CT, census tract; RCP, ready-to-consume products; ICC, intra-class correlation coefficient.

Model 1, null; model 2, individual-level variables (age, gender and mother's education level); model 3, socio-economic status at the neighbourhood level (mean years of household head's education level - all CT); model 4, first food environment variable (proportion of Higher \% RCP food stores); model 5, second food environment variable (average number of items classified as RCP in the food stores); model 6, third food environment variable (proportion of items classified as RCP in the food stores).

${ }^{\star} P<0.05,{ }^{\star \star} P<0.01,{ }^{\star \star \star} P<0.001$.

in the proportion of RCP available in the establishments (model 6) were associated with a reduction of $1 \cdot 1,8.4$ and $1.7 \%$, respectively, in the consumption of UF-MPF by children surveyed. In these models, neighbourhood-level SES was positively associated with the proportion of UF-MPF consumed. After inserting all variables in the models, the intra-class correlation coefficient values were 0.01 or lower (Table 5).

\section{Discussion}

The current study investigated the association between the food store environment and the consumption of foods with different degrees of industrial processing by children living in an urban setting in Brazil. Although studies have evaluated the relationship between healthy and unhealthy food availability and food consumption in high-income countries, little information regarding this relationship is available for low- and middle-income countries ${ }^{(33,55,63)}$. The present study fills gaps in the literature not only because it was conducted in a middle-income country, but also because it is the first that examines the relationship between the food environment and food consumption by using a classification of foods based on the nature, extent and purpose of their industrial processing. This criterion was chosen since it is suggested that modern nutrition science focused on the identification and isolation of nutrients is not able to totally explain the relationship between diet and health ${ }^{(26,48,49)}$. Additionally, consideration of the degree of industrial processing of foods may help to identify existing constraints in agriculture and food systems, and to generate evidence to promote nutritionfriendly food environments ${ }^{(64,65)}$. The proportion of consumption of RCP found in this sample is similar to results presented in previous studies conducted in $\mathrm{Brazil}^{(25,66)}$ and supports research that has demonstrated a rapid increase in the consumption of processed and ultraprocessed food products in low- and middle-income countries $^{(21,22,67)}$.

Higher availability of RCP in surrounding neighbourhoods was associated with both an increase in consumption of these foods and also a decrease in healthier food consumption (UF-MPF) among children. Additionally, the current study found that the proportion of RCP food sources and the number/proportion of RCP within those sources are significant predictors of RCP consumption. The association between RCP availability in food stores and their consumption by children is consistent with prior studies conducted in the $\mathrm{UK}^{(33,55)}$ and Canada ${ }^{(35)}$ that have demonstrated associations between the availability of unhealthy types of food stores in the neighbourhood where children live and the consumption of highly processed foods, such as soft drinks, non-carbonated 'fruit' 
drinks, sweets, chocolates and crisps. Also, the negative association between proximity of fast-food and convenience stores and fruit and vegetable intake by children was previously observed in Australia ${ }^{(60)}$ and supports the hypothesis that exposure to a built environment that offers a variety of energy-dense and processed foods can discourage the consumption of healthy foods among this age group. The relationship between food environments and obesity in higher-income countries may serve to predict trends in developing countries, whose processed and ultra-processed food product sales have increased in recent years. Recent research demonstrated that while sales growth of RCP began to decline in North America and Western Europe in 2012, it increased by $114.9 \%$ throughout Asia and the Pacific and by $50 \%$ in Latin America ${ }^{(32)}$ during the same period. Taking into account these trends and our results, interventions should focus on decreasing the availability of unhealthier food sources and on reducing the proportion of RCP within those sources as a means to improving diet among children not only in Santos, but also other Brazilian urban areas.

Parental education level, a proxy of SES, was positively associated with UF-MPF consumption. Previous studies demonstrated that both the availability of healthier foods in the home and the consumption of healthier options, such as fruits and vegetables, were strongly associated with both individual- and household-level income and educational level $^{(68-70)}$.

UF-MPF neighbourhood availability was not associated with consumption of UF-MPF. Contrary to our results, research conducted with adults in the city of Sao Paulo found that living close to stores and/or markets where fruits and vegetables were available was associated with higher prevalence of regular consumption of these foods, regardless of their price or quality ${ }^{(71)}$. However, it is important to emphasize that our study has not evaluated the association between the availability and consumption of fruits and vegetables, but of all food items classified as UF-MPF, such as pulses, nuts and seeds, unprocessed meats, milk, etc.; which could explain part of the differences among these results. Additionally, taste preferences for fast foods could influence the selection of unhealthy foods within an environment where food outlets offering energy-dense food items are located close to children's homes ${ }^{(72)}$. Although there are many variables within the family setting that can influence children's eating behaviour, such as foods made available to children, parents' eating behaviours and child feeding strategies utilized, some studies demonstrate that children can also affect their parents' grocery purchases, through asking nicely, negotiating and begging ${ }^{(73)}$. These practices have been associated with advertisements, including packaging, characters and commercials ${ }^{(74,75)}$; and with the purchase of unhealthy items such as sweets, snack foods and cereals $^{(76)}$.
Our findings indicate that interventions aimed at only increasing healthier options in the neighbourhood food environment will not necessarily guarantee their purchase and consumption, especially among lower-income groups. Other important predictors of food consumption, such as price and convenience of healthier foods, should be addressed ${ }^{(77)}$. For example, increasing the availability of healthy foods will have limited impact on consumption if the foods within these environments are not affordable. Additionally, prior research conducted with the mothers and caregivers of the children investigated in the current study demonstrated that the acquisition of minimally processed foods was associated with perceived availability and variety of fresh produce in the neighbourhood ${ }^{(78)}$. Interventions must consider possible barriers to healthier food consumption among lower-income subgroups, including affordability, cultural acceptability, convenience (e.g. time to prepare foods, etc.) and perceptions on cost, availability and quality, in order to reduce health disparity and inequity gaps ${ }^{(79,80)}$. Also, interventions in the school food environment (which include when and where children obtain foods and the types of options available during the school day), through making UF-MPF more available and banning the sales of RCP, should also be considered as an important driver to promote healthier consumption patterns among children ${ }^{(81)}$.

Although the existence of supermarkets in the neighbourhood has been positively associated with fruit and vegetable availability and consumption in high- and middleincome countries ${ }^{(78,82-85)}$, the contribution that these food stores make to the availability of RCP cannot be ignored. The rapid increase and dominance of supermarkets throughout developed areas of Latin America, Africa and Asia in the last few decades has contributed, at least in part, to the increased availability of processed food products at low $\operatorname{cost}^{(21,86-88)}$ and the subsequent shift in consumption from staple and unprocessed foods to energy-dense and ultra-processed foods ${ }^{(21,26,89)}$. Interventions should focus on increasing the proportion of healthier foods compared with unhealthier foods within supermarkets to facilitate healthier food consumption patterns ${ }^{(90,91)}$.

The present study has several strengths. Both environmental and individual data were collected simultaneously, by using standardized techniques, intensively trained interviewers and previously validated instruments. The types of food stores and the availability of foods were investigated through direct observations, which increased the validity of the neighbourhood environmental measures. Although previous studies evaluated both community and consumer food environment in Brazil ${ }^{(71,85)}$, ours is the first to use a classification of the foods available in the food environment and consumed by children based on the extent and purpose of their industrial processing.

The study also has a few limitations. First, a crosssectional design was used, limiting causal inferences. As mentioned by Hammond and Dubé( ${ }^{(92)}$, the drivers of 
food and nutrition security are complex, multilevel, multisectoral and heterogeneous, and are a particular challenge for scientific study. In order to accelerate progress in this field, effective theories and methods to model the existent complexities, such as integrative longitudinal databases on specific processes and outcomes of agri-food, health and environmental systems, need to be developed, tested and used $^{(92,93)}$. Second, the neighbourhood food environment measure included only those food stores within the households' surrounding area, by using buffers as administrative boundaries. This method may limit the true representation of the environments to which individuals are exposed by not taking into account their mobility ${ }^{(94)}$. However, previous investigation with the mothers of our participants revealed an association between the purchase of minimally processed foods and the frequency of walking to food sources from their home ${ }^{(78)}$. Third, we were not able to take into account information regarding the household nutrition environment and other potential covariates related to children's eating behaviours. Future studies should examine the relationships between environmental factors and other influences on children's minimally processed foods consumption, such as individual preferences, parental influences and availability within home. Fourth, at the time of the study's data collection and analysis, the instrument that captures food availability in restaurants had not yet been validated. As a result, only food stores located in the surrounding areas of children's homes were evaluated, although they represent just one part of the whole food environment. Finally, the multilevel models were not adjusted to school kind, since this information was not assessed. Public schools have a school standardized food programme, which is different from the coffee shops and cafeterias available in the majority of private schools in Brazil. However, the differences among the school meals/food items available in these institutions were taken into account when analysing the food consumption of children.

The results suggest that food policies and interventions aiming to reduce RCP consumption in settings similar to the city of Santos may be more effective if they focus on reducing RCP availability in food stores and increasing low-cost and healthy alternatives. Additionally, interventions to make UF-MPF more affordable and accessible to lower-SES populations within existing environments may be more effective than increasing the quantity of UF-MPF food sources.

\section{Acknowledgements}

Acknowledgements: The authors wish to thank all the families that participated in the study and the interviewers for their cooperation in collecting the data. Financial support: This work was supported by Sao Paulo State Foundation for Research Support (FAPESP; grant numbers
2009/01361-1 and 2010/04471-0); and by Coordination for the Improvement of Higher Level Personnel (CAPES; REUNI). FAPESP and CAPES had no role in the design, analysis or writing of this article. Conflict of interest: None. Authorship: F.H.M.L. and P.A.M. designed the study, conducted the data analysis and wrote the paper. E.C.C., D.S.C.A. and M.A.O. helped in the data collection and data analysis. N.B. helped to write the paper. Ethics of human subject participation: This study was approved by the Ethics and Research Committee of the Federal University of Sao Paulo (protocol numbers CEP 0275/09 and 0276/09). All participants provided written informed consent.

\section{References}

1. Ng M, Fleming T, Robinson M et al. (2014) Global, regional, and national prevalence of overweight and obesity in children and adults during 1980-2013: a systematic analysis for the Global Burden of Disease Study 2013. Lancet 384, 766-781.

2. Instituto Brasileiro de Geografia e Estatística (2010) Pesquisa de Orçamentos Familiares 2008-2009 - Antropometria e estado nutricional de crianças, adolescentes e adultos no Brasil. http://www.ibge.gov.br/home/estatistica/populacao/ condicaodevida/pof/2008_2009_encaa/pof_20082009_encaa. pdf (acessed October 2014).

3. World Health Organization (2012) Prioritizing Areas for Action in the Field of Population-Based Prevention of Childhood Obesity: A Set of Tools for Member States to Determine and Identify Priority Areas for Action. Geneva: WHO.

4. Penney TL, Almiron-Roig E, Shearer C et al. (2014) Modifying the food environment for childhood obesity prevention: challenges and opportunities. Proc Nutr Soc $\mathbf{7 3}$, 226-236.

5. Koplan JP \& Dietz WH (1999) Caloric imbalance and public health policy. JAMA 282, 1579-1581.

6. Koplan JP, Liverman CT \& Kraak VI (2005) Preventing childhood obesity: health in the balance. J Am Diet Assoc 105, 131-138.

7. World Health Organization (2004) Global Strategy on Diet, Physical Activity and Health. Geneva: WHO.

8. Velasquez-Melendez G, Mendes LL \& Padez CM (2013) Built environment and social environment: associations with overweight and obesity in a sample of Brazilian adults. Cad Saude Publica 29, 1988-1996.

9. Gamba RJ, Schuchter J, Rutt C et al. (2015) Measuring the food environment and its effects on obesity in the United States: a systematic review of methods and results. J Community Health 40, 464-475.

10. Gilliland JA, Rangel CY, Healy MA et al. (2012) Linking childhood obesity to the built environment: a multi-level analysis of home and school neighbourhood factors associated with body mass index. Can J Public Health 103, 9 Suppl. 3, eS15-eS21.

11. de Carvalho Cremm EC, Marrocos Leite FH, de Abreu DSC et al. (2012) Factors associated with overweight in children living in the neighbourhoods of an urban area of Brazil. Public Health Nutr 15, 1056-1064.

12. Glanz K, Sallis JF, Saelens BE et al. (2005) Healthy nutrition environments: concepts and measures. Am J Health Promot 19, 330-333.

13. Glanz K, Sallis JF, Saelens BE et al. (2007) Nutrition Environment Measures Survey in stores (NEMS-S): development and evaluation. Am J Prev Med 32, 282-289. 
14. Story M, Kaphingst KM, Robinson-O'Brien R et al. (2008) Creating healthy food and eating environments: policy and environmental approaches. Annu Rev Public Health 29, 253-272.

15. Richard L, Gauvin L \& Raine K (2011) Ecological models revisited: their uses and evolution in health promotion over two decades. Annu Rev Public Health 32, 307-326.

16. Huang TT, Drewnosksi A, Kumanyika S et al. (2009) A systems-oriented multilevel framework for addressing obesity in the 21st century. Prev Chronic Dis 6, A82.

17. Naylor PJ, Bridgewater L, Purcell M et al. (2010) Publically funded recreation facilities: obesogenic environments for children and families? Int J Environ Res Public Health 7, 2208-2221.

18. Horsley JA, Absalom KA, Akiens EM et al. (2014) The proportion of unhealthy foodstuffs children are exposed to at the checkout of convenience supermarkets. Public Health Nutr 17, 2453-2458.

19. Poti JM, Slining MM \& Popkin BM (2014) Where are kids getting their empty calories? Stores, schools, and fast-food restaurants each played an important role in empty calorie intake among US children during 2009-2010. J Acad Nutr Diet 114, 908-917.

20. Leite FHM, Oliveira MA, Cremm EC et al. (2012) Availability of processed foods in the perimeter of public schools in urban areas. J Pediatr (Rio J) 88, 328-334.

21. Monteiro CA, Moubarac JC, Cannon G et al. (2013) Ultra-processed products are becoming dominant in the global food system. Obes Rev 14, 21-28.

22. Stuckler D, McKee M, Ebrahim S et al. (2012) Manufacturing epidemics: the role of global producers in increased consumption of unhealthy commodities including processed foods, alcohol, and tobacco. PLoS Med 9, e1001235.

23. Moubarac JC, Claro RM, Baraldi LG et al. (2013) International differences in cost and consumption of readyto-consume food and drink products: United Kingdom and Brazil, 2008-2009. Glob Public Health 8, 845-856.

24. Moubarac JC, Martins AP, Claro RM et al. (2013) Consumption of ultra-processed foods and likely impact on human health. Evidence from Canada. Public Health Nutr 16, 2240-2248.

25. Martins AP, Levy RB, Claro RM et al. (2013) Increased contribution of ultra-processed food products in the Brazilian diet (1987-2009). Rev Saude Publica 47, 656-665.

26. Monteiro CA, Levy RB, Claro RM et al. (2011) Increasing consumption of ultra-processed foods and likely impact on human health: evidence from Brazil. Public Health Nutr $\mathbf{1 4}$, $5-13$.

27. Ifland JR, Preuss HG, Marcus MT et al. (2009) Refined food addiction: a classic substance use disorder. Med Hypotheses 72, 518-526.

28. Rauber F, Campagnolo PD, Hoffman DJ et al. (2015) Consumption of ultra-processed food products and its effects on children's lipid profiles: a longitudinal study. Nutr Metab Cardiovasc Dis 25, 116-122.

29. Tavares LF, Fonseca SC, Garcia Rosa ML et al. (2012) Relationship between ultra-processed foods and metabolic syndrome in adolescents from a Brazilian Family Doctor Program. Public Health Nutr 15, 82-87.

30. Canella DS, Levy RB, Martins AP et al. (2014) Ultra-processed food products and obesity in Brazilian households (2008-2009). PLoS One 9, e92752.

31. Moreira PV, Baraldi LG, Moubarac JC et al. (2015) Comparing different policy scenarios to reduce the consumption of ultra-processed foods in UK: impact on cardiovascular disease mortality using a modelling approach. PLoS One 10, e0118353.

32. Pan American Health Organization (2015) Ultra-Processed Food and Drink Products in Latin America: Trends, Impact on Obesity, Policy Implications. Washington, DC: PAHO.
33. Jennings A, Welch A, Jones AP et al. (2011) Local food outlets, weight status, and dietary intake: associations in children aged 9-10 years. Am J Prev Med 40, 405-410.

34. Rahman T, Cushing RA \& Jackson RJ (2011) Contributions of built environment to childhood obesity. Mt Sinai J Med 78, 49-57.

35. Pabayo R, Spence JC, Cutumisu N et al. (2012) Sociodemographic, behavioural and environmental correlates of sweetened beverage consumption among preschool children. Public Health Nutr 15, 1338-1346.

36. Li Y, Robinson LE, Carter WM et al. (2014) Childhood obesity and community food environments in Alabama's Black Belt region. Child Care Health Dev 41, 668-676.

37. Oreskovic NM, Kuhlthau KA, Romm D et al. (2009) Built environment and weight disparities among children in highand low-income towns. Acad Pediatr 9, 315-321.

38. Instituto Brasileiro de Geografia e Estatística (2010) Pesquisa de orçamentos familiares 2008-2009. Despesas, rendimentos e condições de vida. http://www.ibge.gov.br/home/estatistica/ populacao/condicaodevida/pof/2008_2009/POFpublicacao. pdf (accessed October 2014).

39. Fidelis CMF \& Osório MM (2007) Consumo alimentar de macro e micronutrientes de crianças menores de cinco anos no Estado de Pernambuco, Brasil. Rev Bras Saude Mater Infant 7, 63-74.

40. Bernardi JR, Cezaro CD, Fisberg RM et al. (2010) Estimation of energy and macronutrient intake at home and in the kindergarten programs in preschool children. $J$ Pediatr (Rio J) 86, 59-64.

41. Dodd KW, Guenther PM, Freedman LS et al. (2006) Statistical methods for estimating usual intake of nutrients and foods: a review of the theory. J Am Diet Assoc 106, $1640-1650$.

42. Slater B, Marchioni DL \& Fisberg RM (2004) Estimating prevalence of inadequate nutrient intake. Rev Saude Publica 38, 599-605.

43. Conway JM, Ingwersen LA, Vinyard BT et al. (2003) Effectiveness of the US Department of Agriculture 5-step multiple-pass method in assessing food intake in obese and nonobese women. Am J Clin Nutr 77, 1171-1178.

44. Conway JM, Ingwersen LA \& Moshfegh AJ (2004) Accuracy of dietary recall using the USDA five-step multiple-pass method in men: an observational validation study. J Am Diet Assoc 104, 595-603.

45. Lopes RPS \& Botelho RBA (2008) Álbum Fotográfico de Porções Alimentares. São Paulo: Metha.

46. Fisberg RM \& Slater B (2002) Manual de Receitas e Medidas Caseiras para Cálculo de Inquéritos Alimentares: Manual Elaborado para Auxiliar o Processamento de Dados de Inquéritos Alimentares. São Paulo: Signus.

47. Pinheiro AVB (2004) Tabela para Avaliação de Consumo Alimentar em Medidas Caseiras, 5th ed. Rio de Janeiro: Atheneu.

48. Monteiro CA, Levy RB, Claro RM et al. (2010) A new classification of foods based on the extent and purpose of their processing. Cad Saude Publica 26, 2039-2049.

49. Ministry of Health of Brazil, Secretariat of Health Care, Primary Health Care Department (2014) Dietary Guidelines for the Brazilian Population. http://189.28.128.100/dab/ docs/portaldab/publicacoes/guia_alimentar_populacao_ingles. pdf (acessed October 2014).

50. Moubarac JC, Parra DC, Cannon G et al. (2014) Food classification systems based on food processing: significance and implications for policies and actions: a systematic literature review and assessment. Curr Obes Rep 3, 256-272.

51. Martins PA, Cremm EC, Leite FHM et al. (2013) Validation of an adapted version of the nutrition environment measurement tool for stores (NEMS-S) in an urban area of Brazil. J Nutr Educ Behav 45, 785-792. 
52. Fonseca F (2013) Retail Foods, Brazil. Report no. BR13011. Global Agricultural Information Network. Brazil: USDA Foreign Agricultural Service.

53. Ghisi FA, Silveira JAG, Kristensen T et al. (2008) Horizontal alliances amongst small retailers in Brazil. Br Food $J \mathbf{1 1 0}$, 514-538.

54. Timperio A, Ball K, Roberts R et al. (2008) Children's fruit and vegetable intake: associations with the neighbourhood food environment. Prev Med 46, 331-335.

55. Skidmore P, Welch A, van Sluijs E et al. (2010) Impact of neighbourhood food environment on food consumption in children aged 9-10 years in the UK SPEEDY (Sport, Physical Activity and Eating behaviour: Environmental Determinants in Young people) study. Public Health Nutr 13, 1022-1030.

56. Lioret S, Betoko A, Forhan A et al. (2015) Dietary patterns track from infancy to preschool age: cross-sectional and longitudinal perspectives. J Nutr 145, 775-782.

57. Schmidt M, Affenito SG, Striegel-Moore R et al. (2005) Fast-food intake and diet quality in black and white girls: the National Heart, Lung, and Blood Institute Growth and Health Study. Arch Pediatr Adolesc Med 159, 626-631.

58. de Aquino RC \& Phillippi ST (2002) Association of children's consumption of processed foods and family income in the city of São Paulo, Brazil. Rev Saude Publica 36, 655-660.

59. Laxer RE \& Janssen I (2014) The proportion of excessive fast-food consumption attributable to the neighbourhood food environment among youth living within $1 \mathrm{~km}$ of their school. Appl Physiol Nutr Metab 39, 480-486.

60. Timperio A, Ball K, Roberts R et al. (2008) Children's fruit and vegetable intake: associations with the neighbourhood food environment. Prev Med 46, 331-335.

61. Jeffery RW, Baxter J, McGuire M et al. (2006) Are fast food restaurants an environmental risk factor for obesity? Int $J$ Behav Nutr Phys Act 3, 2.

62. Wang R \& Shi L (2012) Access to food outlets and children's nutritional intake in urban China: a difference-in-difference analysis. Ital J Pediatr 38, 30.

63. Van Hulst A, Barnett TA, Gauvin L et al. (2012) Associations between children's diets and features of their residential and school neighbourhood food environments. Can J Public Health 103, 9 Suppl. 3, eS48-eS54.

64. Global Panel on Agriculture and Food Systems for Nutrition (2014) How Can Agriculture and Food System Policies improve Nutrition? London: Global Panel on Agriculture and Food Systems for Nutrition.

65. Hawkes C, Smith TG, Jewell J et al. (2015) Smart food policies for obesity prevention. Lancet 385, 2410-2421.

66. Louzada MLdC, Martins APB, Canella DS et al. (2015) Impact of ultra-processed foods on micronutrient content in the Brazilian diet. Rev Saude Publica 49, 1-8.

67. Asfaw A (2011) Does consumption of processed foods explain disparities in the body weight of individuals? The case of Guatemala. Health Econ 20, 184-195.

68. Ding D, Sallis JF, Norman GJ et al. (2012) Community food environment, home food environment, and fruit and vegetable intake of children and adolescents. J Nutr Educ Behav 44, 634-638.

69. Jack D, Neckerman K, Schwartz-Soicher O et al. (2013) Socio-economic status, neighbourhood food environments and consumption of fruits and vegetables in New York City. Public Health Nutr 16, 1197-1205.

70. Lucan SC, Hillier A, Schechter CB et al. (2014) Objective and self-reported factors associated with food-environment perceptions and fruit-and-vegetable consumption: a multilevel analysis. Prev Chronic Dis 11, E47.

71. Duran AC, de Almeida SL, Latorre MD et al. (2016) The role of the local retail food environment in fruit, vegetable and sugar-sweetened beverage consumption in Brazil. Public Health Nutr 19, 1093-1102.
72. Shepherd J, Harden A, Rees R et al. (2006) Young people and healthy eating: a systematic review of research on barriers and facilitators. Health Educ Res $\mathbf{2 1}$, 239-257.

73. Huang CY, Reisch LA, Gwozdz W et al. (2016) Pester power and its consequences: do European children's food purchasing requests relate to diet and weight outcomes? Public Health Nutr 19, 2393-2403.

74. McDermott L, O'Sullivan T, Stead M et al. (2006) International food advertising, pester power and its effects. Int J Advert 25, 513-539.

75. Henry HKM \& Borzekowski DLG (2011) The nag factor. J Child Media 5, 298-317.

76. Ogba IE \& Johnson R (2010) How packaging affects the product preferences of children and the buyer behaviour of their parents in the food industry. Young Consum 11, $77-89$.

77. Glanz K, Basil M, Maibach E et al. (1998) Why Americans eat what they do: taste, nutrition, cost, convenience, and weight control concerns as influences on food consumption. J Am Diet Assoc 98, 1118-1126.

78. Vedovato GM, Trude AC, Kharmats AY et al. (2015) Degree of food processing of household acquisition patterns in a Brazilian urban area is related to food buying preferences and perceived food environment. Appetite 87, 296-302.

79. Budd N, Cuccia A, Jeffries JK et al. (2015) B'More Healthy: Retail Rewards - design of a multi-level communications and pricing intervention to improve the food environment in Baltimore City. BMC Public Health 15, 283.

80. Drewnowski A \& Specter SE (2004) Poverty and obesity: the role of energy density and energy costs. Am J Clin Nutr $\mathbf{7 9}$, 6-16.

81. Welker E, Lott M \& Story M (2016) The school food environment and obesity prevention: progress over the last decade. Curr Obes Rep 5, 145-155.

82. Moore LV, Diez Roux AV, Nettleton JA et al. (2008) Associations of the local food environment with diet quality - a comparison of assessments based on surveys and geographic information systems: the multi-ethnic study of atherosclerosis. Am J Epidemiol 167, 917-924.

83. Leone AF, Rigby S, Betterley C et al. (2011) Store type and demographic influence on the availability and price of healthful foods, Leon County, Florida, 2008. Prev Chronic Dis 8, A140.

84. Black C, Ntani G, Inskip H et al. (2014) Measuring the healthfulness of food retail stores: variations by store type and neighbourhood deprivation. Int J Behav Nutr Phys Act 11, 69.

85. Duran AC, Diez Roux AV, Latorre Mdo R et al. (2013) Neighborhood socioeconomic characteristics and differences in the availability of healthy food stores and restaurants in Sao Paulo, Brazil. Health Place 23, 39-47.

86. Gehlhar M \& Regmi A (2005) Factors shaping global food markets. In New Directions in Global Food Markets. Agriculture Information Bulletin no. AIB-794, pp. 5-17 [A Regmi and M Gehlhar, editors]. Washington, DC: US Department of Agriculture.

87. Monteiro CA \& Cannon G (2012) The impact of transnational 'big food' companies on the South: a view from Brazil. PLoS Med 9, e1001252.

88. Reardon T, Timmer P \& Berdegue J (2004) The rapid rise of supermarkets in developing countries: induced organizational, institutional, and technological change in agrifood systems. J Agric Dev Econ 1, 168-183.

89. Popkin BM (2014) Synthesis and implications: China's nutrition transition in the context of changes across other low- and middle-income countries. Obes Rev 15, 60-67. 
90. Surkan PJ, Tabrizi MJ, Lee RM et al. (2016) Eat Right-Live Well! Supermarket intervention impact on sales of healthy foods in a low-income neighborhood. J Nutr Educ Behav 48, 112-121.

91. Gittelsohn J, Vijayadeva V, Davison N et al. (2010) A food store intervention trial improves caregiver psychosocial factors and children's dietary intake in Hawaii. Obesity (Silver Spring) 18, S84-S90.

92. Hammond RA \& Dubé L (2012) A systems science perspective and transdisciplinary models for food and nutrition security. Proc Natl Acad Sci U S A 109, 12356-12363.

93. Castellani B, Rajaram R, Buckwalter JG et al. (2015) Place and Health as Complex Systems: A Case Study and Empirical Test. Cham, Switzerland: Springer.

94. Perchoux C, Chaix B, Cummins S et al. (2013) Conceptualization and measurement of environmental exposure in epidemiology: accounting for activity space related to daily mobility. Health Place 21, 86-93. 